\title{
Parental Infertility: Impact of the Quality of the Relation between Parents and Adopted Children
}

\section{Alessia Puddu ${ }^{1}$, Stefania Baldassari ${ }^{1}$, Maria Fenicia Vescio ${ }^{2}$, Rosaria Giampaolo 3 , Andrea Finocchi ${ }^{4}$, Hyppolite K. Tchidjou ${ }^{*}$}

\author{
${ }^{1}$ Analitic Etnopsychology Project (ETNA), Rome, Italy \\ ${ }^{2}$ Epidemiology Unit, Department of Infectious Diseases, National Institute for Health, Rome, Italy \\ ${ }^{3}$ Department of Paediatric Medicine, Bambino Gesù Children's Hospital, Rome, Italy \\ ${ }^{4}$ University Department of Pediatrics (DPUO), Bambino Gesù Children's Hospital, Rome, Italy \\ ${ }^{5}$ Pediatric Services, Amiens University Hospital, Amiens, France \\ Email: *tchidjoukuekou.hyppolite@chu-amiens.fr
}

How to cite this paper: Puddu, A., Baldassari, S., Vescio, M. F., Giampaolo, R., Finocchi, A., \& Tchidjou, H. K. (2021). Parental Infertility: Impact of the Quality of the Relation between Parents and Adopted Children. Advances in Applied Sociology, 11, 185-193.

https://doi.org/10.4236/aasoci.2021.114014

Received: February 9, 2021

Accepted: April 18, 2021

Published: April 21, 2021

Copyright $\odot 2021$ by author(s) and Scientific Research Publishing Inc. This work is licensed under the Creative Commons Attribution International License (CC BY 4.0).

http://creativecommons.org/licenses/by/4.0/ (c) (i) Open Access

\begin{abstract}
Background: Infertility-related stress is often greatest for heterosexual couples who pursue more extensive fertility treatments as In Vitro Fertilization (IVF) than other couples. Treatments can affect the development of the parent-child relationship of couples who then decided to adopt a child. Aims: This study was performed to demonstrate that the couples who underwent In Vitro Fertilization (IVF) before adopting a child, could have more difficulties in the relationship with the adopted child than the other couples. Methods: Parents were interviewed by a pediatrician and by a psychologist to collect socio-economic, clinical and psychological information regarding their own health and that of their children. A Multiple Indicators Multiple Causes (MIMIC) model was carried out. Results: Couple conflict and previous infertility treatment are directly related to Difficult Home Environment. High conflict couples and couples who underwent a fertility treatment have a higher mean value for Difficult Home Environment. Conclusions: These findings indicate that couples who underwent IVF had a higher level of stress and more difficulty in the development of a healthy parent-child relationship during and immediately after adoption.
\end{abstract}

\section{Keywords}

In Vitro Fertilization, Family Relations, Adoption, Infertility

\section{Introduction}

Socio-cultural changes which lead couples to have a child later in life, at ages in 
which natural fertility is expected to decline, are one of the major reasons for the dramatic growth in infertility in the past decades (Zurlo, 2009). World Health Organization reported that one in four couples experience infertility. For this reason, assisted reproductive technologies (ART) are increasingly being used to overcome fertility problems (De Mouzon et al., 2010). However, using this method is not without consequences at the psychological level (Ben Shlomo et al., 2017) and there is a pressing need for a better understanding of these issues to prevent the negative effects of past ART on the development of a healthy parent-child-relationship in couples adopting a child (Smorti \& Smorti, 2013).

Infertility may hamper the physical and mental health of both men and women and involve their social relationships (McQuillan et al., 2003, Iordachescu et al., 2021). Heterosexual couples who pursue more extensive fertility treatments like IVF treatments, face greater stress than those who undergo other less invasive treatments. Therefore, a long period of infertility correlates with high level of distress (Iordachescu et al., 2021). Indeed, these couples struggle to integrate their experiences of infertility and the transition to become a possible parent (Allan et al., 2019). Couples who undergo medical treatment for infertility, and particularly women, tend to use more experiential avoidance and self-judgment mechanisms and less emotional/detached coping style. Data showed that couples with infertility applying for adoption showed higher self-compassion (Cunha, 2016). Gender may moderate the infertility-related stress such that women may be more affected than men when treated for infertility (Galhardo et al., 2020; Smorti \& Smorti, 2013; Schneider \& Forthofer, 2005; Anderson et al., 2003). Some studies comparing unfertile and fertile couples revealed higher levels of depression and anxiety in women and men who underwent ART in the past compared to those who conceived spontaneously (Hsu \& Kuo, 2002). It has known that infertility and IVF represent per se a stressful condition (Schneider \& Forthofer, 2005). Moreover, Canzi et al. (2018) showed that high level of parents' stress could even influence the improvements in child growth. Little research has been examined parenthood among couples who adopt a child after IVF. Therefore, the aim of this study was to analyze whether the unsuccessful IVF treatments may affect the development of a healthy parent-child relationship in couples adopting a child.

To reach this aim we carried out a cross-sectional study in couples who adopted a child.

\section{Materials and Methods}

\subsection{Study Design}

Cross-sectional data was obtained from the International Adoption Unit of the Bambino Gesù Children's Hospital, Rome-Italy between August 2012 and March 2013. We evaluated 55 infants aged 3 months or younger which were internationally adopted in Italy and their adoptive parents.

Parents were first interviewed by a pediatrician to collect socio-economic and 
clinical information: 1) socio-economic information included parents' age and their current occupation; 2) clinical information included parents' medical and sexual/reproductive history (number of children and abortions, number of previous pregnancies, diagnosis of infertility and medical records regarding previous fertility treatments) and then by a psychologist in order to identify critical areas in the child-parents-relationship (in the specific to qualify their first impact with the child and to define their current relationship). In addition, they were asked to rate their own relationship with the adopted child.

\subsection{Statistical Analysis}

We carried out a Multiple Indicators Multiple Causes (MIMIC) model of children home environment (StataCorp., 2011; Acock, 2013). The MIMIC model is a special case of the structural equation modelling (SEM) and consists of two components: a measurement model which describes indicator variables related to the latent variables (i.e. not directly measured, but represented by the overlapping variance of measured variables) (1) and a structural model which analyses the causal relationships among latent variables and predictors (2). We hypothesized that home environment leads to parents' ratings (self-assessed) and to level of the psychologist's ratings. We combined 3 formative indicators (IVF, couples with conflict and acceptance of a child with problems) with 4 reflective indicators (psychologist's ratings, parents' ratings).

MIMIC analyses were conducted in STATA 13 (StataCorp., 2013). The ML procedure was used. Confirmatory Factor Analysis (CFA) was performed, in order to establish a valid model prior to the addition of formative indicators. A non-statistical significance of the $\chi^{2}$-test relative to the degrees of freedom indicated that the implied theoretical model significantly reproduced the sample variance-covariance relationships in the matrix. Goodness of fit for our model was assessed by two indices: the comparative fit indices (CFIs) and the root mean square error of approximation (RMSEA), which are in wide use and known to be relatively unaffected by sample size.

\section{Results}

Demographic characteristics of children are reported in Table 1. 35 (63\%) children were male and 20 (36\%) females. Children median age was 5 (interquartile rage-iqr: 3 - 9). 24 (43\%) children were aged less than 4 years, 21 (38\%) had between 4 and 9 years and $10(18 \%)$ were aged 10 years or older. $29(53 \%)$ children were from East Europe, 4 (7\%) from South America, 3 (15\%) from Asia and 4 (25\%) from Africa.

Mothers and fathers median age were 45 (iqr: 41 - 49) and 47 (iqr: 44 - 49) respectively (see Table 2). $21 \%$ of mothers and $30 \%$ of fathers were employed in high levels jobs and $65 \%$ of mothers and $69 \%$ of fathers in low level ones. $9 \%$ of mothers were housewives and $3 \%$ were unemployed. In 32 (58\%) couples at least one of the partner was infertile or sub-fertile. 16 (53\%) IVF were carried out in 
Table 1. Demographic characteristics of the children.

\begin{tabular}{ccc}
\hline & N & $\%$ \\
\hline age, years & 5 & \\
median (iqr) & 6.16 & $(3-9)$ \\
mean (sd) & 24 & $(43)$ \\
$0-4$ & 21 & $(38)$ \\
$4-9$ & 10 & $(18)$ \\
$10+$ & 20 & $(36)$ \\
Girls & 35 & $(63)$ \\
Boys & 35 \\
\hline
\end{tabular}

Table 2. Demographic characteristics of the parents.

\begin{tabular}{ccccc}
\hline & \multicolumn{3}{c}{ mothers } & \multicolumn{3}{c}{ fathers } \\
\cline { 2 - 5 } & $\mathbf{N}$ & $\%$ & $\mathbf{N}$ & $\%$ \\
\hline age, years & & & & \\
median (iqr) & 45 & $(41-49)$ & 47 & $(44-49)$ \\
mean (sd) & 45.51 & $(5.19)$ & 46.62 & $(4.09)$ \\
housewives & 5 & $(9)$ & & \\
self-employed & 12 & $(21)$ & 17 & $(30)$ \\
employed & 36 & $(65)$ & 38 & $(69)$ \\
unemployed & 2 & $(3)$ & & \\
\hline
\end{tabular}

couples in which at least one of the partner was infertile or sub-fertile and 14 (47\%) in couples in which each partner was independently fertile but the couples were not able to conceive.

\subsection{Confirmatory Factor Analysis}

The standardized loadings for the measurement of difficult home environment went from 0.86 to 0.95 and were all highly significant as shown in Table 3. The reliability of the items measuring the latent variable Difficult Home Environment was 0.85 in the CFA model, meaning that the true score accounted for $85 \%$ of the variation in the scale items used.

\subsection{Multiple Indicators Multiple Causes (MIMIC) Modelling}

High conflict couples and couples who underwent a fertility treatment had a higher mean value for Difficult Home Environment by 0.44 and 0.35 respectively (see Table 3). Conversely couples willing to accept a child with problems had a lower mean value for Difficult Home Environment by 0.35 . The effects were significant at better than the $5 \%$ level. As suggested by the modification indices we allowed father clinical psychological assessment-mother clinical psychological assessment, father clinical psychological assessment-self-reported father child 
Table 3. Results from the MIMIC model.

\begin{tabular}{|c|c|c|c|}
\hline Endogenous outcome & \multicolumn{2}{|c|}{ Estimates } & \multirow{2}{*}{$p$} \\
\hline DIFFICULT HOME ENVIRONMENT & unstandardized & standardized & \\
\hline \multicolumn{4}{|l|}{ Covariates and significant factor effects on each factor } \\
\hline father psychol assess-factor & 1 & 0.86 & $<0.001$ \\
\hline father self reported-factor & 1.11 & 0.95 & $<0.001$ \\
\hline mother psychol assess-factor & 1.02 & 0.88 & $<0.001$ \\
\hline mother self-reported-factor & 1.00 & 0.89 & $<0.001$ \\
\hline IVF & 0.31 & 0.35 & 0.002 \\
\hline accept child with problems & -0.30 & -0.35 & 0.005 \\
\hline couple conflict & 0.50 & 0.44 & $<0.001$ \\
\hline \multicolumn{4}{|l|}{ variances } \\
\hline var (e. father psychol assess) & 0.06 & 0.86 & \\
\hline $\operatorname{var}$ (e. father self reported) & 0.02 & 0.95 & \\
\hline var (e. mother psychol assess) & 0.06 & 0.15 & \\
\hline $\operatorname{var}$ (e. mother self reported) & 0.05 & 0.43 & \\
\hline var (e. difficult Home Environment) & 0.09 & 1 & \\
\hline \multicolumn{4}{|l|}{ Covariances } \\
\hline cov (e. father psychol assess, e. mother psychol assess) & 0.05 & 0.76 & 0.001 \\
\hline cov (e. father psychol assess, e. father self reported) & 0.02 & 0.46 & 0.201 \\
\hline cov (e. mother psychol assess, e. mother self reported) & -0.02 & -0.30 & 0.252 \\
\hline
\end{tabular}

relationship and mother clinical psychological assessment-self-reported mother-child relationship to be correlated. These covariances indicate relationships not captured by the current model (i.e. father clinical psychological assessment and mother clinical psychological assessment may be causally related or their residuals may be correlated) and make sense conceptually. There were no other modification indices greater than $3.84 .49 \%$ of the variance in the latent variable Difficult home environment was explained in the full MIMIC model. This model provided a reasonably good fit to the data. CFI was above 0.95 and RMSEA was below 0.05 , which represents the amount of variance not accounted for by the model. Overall, the addition of covariates (couple conflict, previous infertility treatment and willingness to accept a child with problems) did not affect the loadings of the items father clinical psychological assessment, mother clinical psychological assessment, self-reported father-child relationship and self-reported mother-child relationship on Difficult Home Environment. Adding fathers and mothers age and their current occupation, child age, sex and country of origin did not improve the fit of the model.

In summary, the results confirmed that couples with a past history of IVF treatments were more likely to experience relationship problems with the adopted child than those not undergoing IVF treatments. The addition of cova- 
riates did not affect the loadings of the items, but have shown that if one partner has unresolved feelings about infertility these symptoms may persist, after the adoption finalization.

\section{Discussion}

The aim of the study was to demonstrate that couples with a past history of IVF treatments, could have more difficulties in the relationship with the adopted child than those who did not undergo IVF. Research demonstrate (Smorti, 2003; Hajela et al., 2016) that couples undergoing IVF treatments experienced increasing levels of stress, with important consequences at the psychological level, in particular in relation to recurrent IVF failure (Gabnai-Nagy et al., 2020; Sumardi \& Ocviyanti, 2020). The study conducted by Galhardo et al. (2016) emphasized the role of perceptions of defeat and entrapment on the psychological adjustment to assisted reproduction and it underlined the development of depressive symptoms in couples. Therefore, it is clear that depressive feeling affects relationships in general. Results from this study confirmed our hypothesis that couples with a past history of IVF treatments were more likely to experience relationship problems with the adopted child than those not undergoing IVF treatments. If one partner has unresolved feelings about infertility these symptoms may persist, or arise occasionally, even many months after the adoption finalization (Goldberg et al., 2009). We can stress that these feelings may have an important impact on the relationship with the child. Data underline how IVF treatments affect women more than men at the emotional level and in particular women tend to experience more depressive symptoms (Galhardo et al., 2020). However, we did not find a significant difference in the psychological well-being and parental attitudes between women and men, thus confirming that when one member of the couple is affected, all the other members of the family may also be affected to some extent (Goldberg et al., 2009). We also found that high conflict couples were more likely to experience problems in their relationship with the adopted child than those not experiencing marital distress (Figure 1). Evidences showed that relationship satisfaction tends to decrease after adoption and that higher conflict predicted higher ambivalence (South et al., 2019). Couples willing to adopt a child with problems were more likely to establish a healthy relationship with their adopted child (Figure 1), perhaps because these couples are less prone to idealize the adopted child than those not willing to adopt a child with problems. Indeed, when expectations become too high these may hinder establishment of a healthy relationship (Foli et al., 2017). Martin and Rosenhauer (2016) demonstrated that mothers adopting a child with problems had high positive adjustment and less depression and anxiety levels. Couples who adopted a child after IVF treatments usually first attempted to have a child naturally, second underwent one or more IVF treatments and third started the procedure for adoption (at least three years in Italy). As a result of these steps parents might be more stressed and tired when the adopted baby's will arrive than the other couples. 


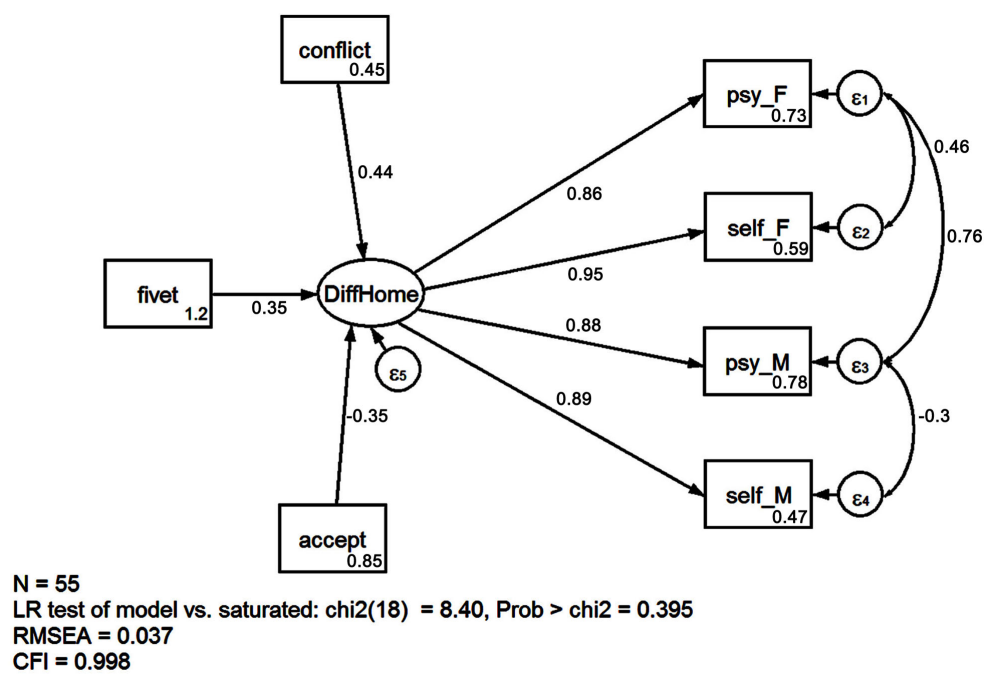

Figure 1. Multiple indicators multiple causes (MIMIC) model of difficult home environment (DiffHome). Reflective indicators: father clinical psychological assessment (psy_F), mother clinical psychological assessment (psy_M), self-reported father-child relationship (self_F) and self-reported mother-child relationship (self_F). Formative indicators: high conflict couple (conflict), IVF (fivet) and agree to accept child with problems (accept). Standardized solution. The latent variable is represented by the ellipse.

This study has some limitations due to the fact that the sample was a small. Future studies conducted on larger patient samples, as well as longitudinal designs, are needed to better investigate the relationship between parental stress and the quality of the parent/child relationship with standardized instrument specifically, the Parenting Stress Index. This instrument is a screening and diagnostic instrument that measures the relative magnitude of stress in the parent-child system (Haskett et al., 2006).

\section{Conclusion}

In conclusion, these findings indicate that couples with a past history of IVF treatments have a high level of stress and a greater difficulty in the development of a parent-child relationship. Therefore, whether these couples would like to adopt a child, they should receive psychological support to reduce future possible difficulties with the adopted child.

\section{Conflicts of Interest}

All of the authors fulfill the authorship criteria and none of the authors have a financial relationship with any commercial entity that could have an interest in the subject of this manuscript.

Confirm that the research meets ethical guidelines, including adherence to the legal requirements.

\section{Contributorships}

Dr. Puddu and Dr. Baldassari contributed to the conception and the design 
of the study, as well as the data acquisition, analysis and interpretation.

Dr. Vescio Maria Fenicia contributed to the statistical analysis and the interpretation of results.

Dr. Hyppolite K. Tchidjou and Dr. Andrea Finocchi contributed to the design of the study, critically reviewed the data and the manuscript for important intellectual content.

\section{References}

Acock, A. C. (2013). Discovering Structural Equation Modeling Using Stata (Revised ed.). College Station, TX: Stata Press.

Allan, H., Mounce, G., Culley, L. A., van den Akker, O. B. A., \& Hudson, R. (2019). Transition to Parenthood after Successful Non-Donor in Vitro Fertilisation: The Effects of Infertility and in Vitro Fertilisation on Previously Infertile Couples' Experiences of Early Parenthood. Health: An Interdisciplinary Journal for the Social Study of Health, Illness and Medicine. https://doi.org/10.1177/1363459319891215

Anderson, K., Sharpe, M., Rattray, A., \& Irvine, D. S. (2003). Distress and Concerns in Couples Referred to a Specialist Infertility Clinic. Journal of Psychosomatic Research, 34, 353-355. https://doi.org/10.1016/S0022-3999(02)00398-7

Ben Shlomo, S., Pascal, M., Taubman-Ben-Ari, O., Azuri, Y., \& Horowitz, E. (2017). Life Satisfaction of Women in Early Stages of Fertility Treatment. Women \& Health, 57, 566-582. https://doi.org/10.1080/03630242.2016.1178682

Canzi, E., Rosnati, R., \& Miller, L. C. (2018). Growth Recovery in Newly Arrived International Adoptees in Italy: Relation to Parenting Stress. Minerva Pediatrica.

Cunha, M., Galhardo, A., \& Pinto-Gouveia, J. (2016). Experiential Avoidance, SelfCompassion, Self-Judgment and Coping Styles in Infertility. Sexual \& Reproductive Healthcare, 10, 41-47. https://doi.org/10.1016/j.srhc.2016.04.001

De Mouzon, J., Goossens, V., Bhattacharya, S., Castilla, J. A., Ferraretti, A. P., Korsak, V., Kupka, M. et al. (2010). European IVF-Monitoring (EIM) Consortium, for the European Society of Human Reproduction and Embryology (ESHRE). Assisted Reproductive Technology in Europe, 2006: Results Generated from European Registers by ESHRE. Human Reproduction, 25, 1851-1862. https://doi.org/10.1093/humrep/deq124

Foli, J. K., Lim, E., \& South, C. S. (2017). Longitudinal Analyses of Adoptive Parents' Expectations and Depressive Symptoms. Research in Nursing and Health, 40, 564-574. https://doi.org/10.1002/nur.21838

Gabnai-Nagy, E., Bugan, A., Bodnar, B., Papp, G., \& Nagy, B. E. (2020). Association between Emotional State Changes in Infertile Couples and Outcome Fertility Treatment. Geburtshilfe und Frauenheilkunde, 80, 200-210. https://doi.org/10.1055/a-0854-5987

Galhardo, A., Alves, J., \& Moura-Ramos, M. (2020). Infertility-Related Stress and Depressive Symptoms-The Role of Experiential Avoidance: A Cross-Sectional Study. Journal of Reproductive and Infant Psychology, 38, 139-150. https://doi.org/10.1080/02646838.2019.1612046

Galhardo, A., Moura-Ramos, M., Cunha, M., \& Pinto-Gouveia, J. (2016). The Infertility Trap: How Defeat and Entrapment Affect Depressive Symptoms. Human Reproduction, 31, 419-426. https://doi.org/10.1093/humrep/dev311

Goldberg, A. E., Downing, J. B., \& Richardson, H. B. (2009). The Transition from Infertility to Adoption: Perceptions of Lesbian and Heterosexual Couples. Journal of Social and Personal Relationships, 26, 938-963. https://doi.org/10.1177/0265407509345652 
Hajela, S., Prasad, S., Kumaran, A., \& Kumar, Y. (2016). Stress and Infertility: A Review. International Journal of Reproduction, Contraception, Obstetrics and Gynecology, 5, 940-943. https://doi.org/10.18203/2320-1770.ijrcog20160846

Haskett, M. E., Ahern, L. S., Ward, C. S., \& Jason, C. (2006). Factor Structure and Validity of the Parenting Stress Index-Short Form. Journal of Clinical Child \& Adolescent Psychology, 35, 302-312. https://doi.org/10.1207/s15374424jccp3502_14

Hsu, Y. L., \& Kuo, B. J. (2002). Evaluations of Emotional Reactions and Coping Behaviors as Well as Correlated Factors for Infertile Couples Receiving Assisted Reproductive Technologies. Journal of Nursing Research, 10, 291-302. https://doi.org/10.1097/01.JNR.0000347610.14166.52

Iordachescu, D. A., Gica, C., Vladislav, E. O., Panaitescu, A. M., Peltecu, G., Furtuna, M. E., \& Gica, N. (2021). Emotional Disorders, Marital Adaptation and the Moderating Role of Social Support for Couples under Treatment for Infertility. Ginekologia Polska, 92, 98-104. https://doi.org/10.5603/GP.a2020.0173

Martin, N. G., \& Rosenhauer, A. M. (2016). Psychological Functioning through the First Six Months in Mothers Adopting from China: Special Needs versus Non-Special Needs. Adoption Quarterly, 19, 261-283. https://doi.org/10.1080/10926755.2015.1121186

McQuillan, J., Greil, A. L., White, L., \& Jacob, M. C. (2003). Frustrated Fertility: Infertility and Psychological Distress among Women. Journal of Marriage and Family, 65, 1007-1018. https://doi.org/10.1111/j.1741-3737.2003.01007.x

Schneider, M. G., \& Forthofer, M. S. (2005). Associations of Psychosocial Factors with the Stress of Infertility Treatment. Health and Social Work, 30, 183-191.

https://doi.org/10.1093/hsw/30.3.183

Smorti, A. (2003). La psicologia culturale. Roma: Carocci.

Smorti, M., \& Smorti, A. (2013). Medical Successes and Couples' Psychological Problems in Assisted Reproduction Treatment: A Narrative Based Medicine Approach. The Journal of Maternal-Fetal and Neonatal Medicine, 26, 169-172. https://doi.org/10.3109/14767058.2012.722728

South, S. C., Lim, E., Jarnecke, A. M., \& Foli, K. J. (2019). Relationship Quality from Preto Post-Placement in Adoptive Couples. Journal of Family Psychology, 33, 64-76. https://doi.org/10.1037/fam0000456

StataCorp. (2011). Stata 12 Structural Equation Modelling Reference Manual. College Station, TX: Stata Press.

StataCorp. (2013). Stata Statistical Software: Release 13. College Station, TX: StataCorp LP. 2013.

Sumardi, H., S., \& Ocviyanti, D. (2020). Bio-Psychosocial Aspects of Infertility: Illustrative Case of Recurrent Failure with Assisted Reproductive Technologies. In Obstetric and Gynecology Case Report (pp. 119-128). Hauppauge, NY: Nova Science Publishers, Inc.

Zurlo, M. C. (2009). Percorsi della filiazione. Milano: Franco Angeli. 